\title{
TEACHER'S MOTIVES IN APPLYING COMMUNICATION ACCOMMODATION STRATEGIES IN SECONDARY ELT CLASS
}

\author{
Almas Rizkika Nabila ${ }^{1}$ \\ Universitas Negeri Surabaya \\ Ahmad Munir ${ }^{2}$ \\ Universitas Negeri Surabaya \\ Syafi'ul Anam ${ }^{3}$ \\ Universitas Negeri Surabaya \\ almas.18005@mhs.unesa.ac.id ${ }^{1}$
}

Submit, 12-05-2020 Accepted, 16-06-2020 Publish, 16-06-2020

\begin{abstract}
The objective of this study is to describe teacher's motives that underlie the use of communication accommodation strategies in secondary ELT class. This study employed a qualitative approach by observing the strategies used in ELT class and interviewing teacher to ask the reason for performing those features. The participant of this study was one English teacher from secondary ELT class. The result showed that teacher used more convergence features in accommodative strategies rather than divergence. Besides, teacher's motives in applying communication accommodation strategies were categorized as affective motives to emphasize the closeness with students and cognitive motives to improve students' understanding in classroom interaction. Teacher was dominant in cognitive motives rather than affective motives when using communication accommodation strategies in secondary ELT class.
\end{abstract}

Keywords: Communication Accommodation Strategies, Affective Motives, Cognitive Motives

\section{INTRODUCTION}

Classroom interaction is important to shape the communication between teacher and students in the whole learning and teaching activities (Markee, 2015). Learning activities will be effective if the communication and interaction between teachers and students occur intensively. According to Kääntä (2015), interaction between teacher and student is a two-way process where the teacher can influence students to create meaning in learning activities and vice versa. Among several components in learning activities, teachers become one of the most important factors to support the success of teaching and learning because they could 
motivate, facilitate, inspire and evaluate students in classroom. It can be said that teachers take a high position in the process of teaching and learning as they become the actor who create the classroom condition (Sedova, Sedlacek, and Svaricek 2016). Teachers need to maintain the classroom interaction using a communicative language to reach the objectives of learning.

Moreover, communicative language could bridge the gap between English teacher and students in ELT context. In other words, some students still have a problem in delivering English language in classroom activities. The previous studies from Rachmawaty \& Hermagustiana (2015) showed that some Indonesians students have a problems in speaking fluency to produce the spoken language in ELT class. The position of English as a foreign language and lack of exposure in daily life make students rare to communicate with the target language and it affects their speaking fluency. It becomes a challenge for English teacher to build the interaction because some students were not actively speaking up in ELT class. It must be underlined that the primary components of classroom interaction are teacher and students. When one component was not actively participated in classroom activity then the teaching and learning process cannot run effectively and intensively. Besides, teachers need to thoughtful and choose the appropriate language in delivering the material to encourage students to be more active especially in oral communication using the target language. Therefore, Matsuda (2017) emphasized that the use of communication strategies is significant for teachers to negotiate the linguistic differences and motivate students' to be more communicative in ELT class. Communication strategy was defined as someone's effort to find a technique to fill the gap between their utterances and other people's linguistic resources to handle the communication breakdowns (Rastegar and Gohari 2016).

Moreover, communication strategies used by English teacher mostly highlight the verbal features rather than nonverbal aspects. Jumiati, Gani, \& Sari (2017) mentioned that the features in communication strategies were limited to describe the nonverbal features. Besides, some previous studies usually applied the theories of communication strategies from Bialystok, Dörnyei, Faerch \& Kasper and Tarone that actually more concern on verbal strategies. In classroom interaction, verbal and nonverbal language cannot be separated from each other since nonverbal sign is highly reliable in the communication process (Bambaeeroo and Shokrpour 2017). Teacher used nonverbal language to deal with many students at classroom as the complement of verbal language. Verbal language relates with spoken or written communication used by teacher in classroom interaction. While nonverbal language embraces the body gesture, expression and eye contact. Therefore, the language input that concerns both verbal and 
nonverbal languages in interaction to reach the effectiveness and intelligible communication is through accommodation (Weizheng 2019).

Accommodation was firstly introduced by Giles then developed to describe the nonverbal domain in interaction and called as communication accommodation theory (CAT) (Gallois and Giles 2015). Communication accommodation theory concerns on the adjustment of people in interaction through convergence and divergence strategy. Besides, the motives in applying communication accommodation strategies in interaction are also important to be explored to see someone's reasons for doing that behavior (Dragojevic, Gasiorek, and Giles 2015). There are two kinds of motives in applying communication accommodation strategies including affective and cognitive motives. Someone could adjust the communication to be more comprehensible to others in every setting of life such as in the office, market and school environment.

Moreover, communication accommodation strategies were applied in classroom interaction between teacher and students. The previous study from Chen (2019) showed that Taiwan teacher used communication accommodation strategies to adjust the interaction with the elderly students in order to avoid the impolite language. Weizheng (2019) identified the way China teachers use communication accommodation strategies to improve their interaction with students in EFL class. Then, Parcha (2014) explored the way students used convergence strategies of communication accommodation through social media as the learning media. The study from Tien (2009) also described that teacher used code-switching in the convergence strategy of communication accommodation to adjust the students' linguistic form in ELT class. In Indonesian context, Maharsi (2010) explored teachers' adjustment through the application of CAT in EFL speaking class.

However, some of the previous studies only described the way teacher performing communication accommodation strategies rather than reveal the motives in applying those strategies in interaction. Since the theory of accommodation is more reliable when it is accompanied by the motives underlying the use of accommodative strategies (Dragojevic et al. 2015). Therefore, this present study explored the communication accommodation strategies used by English teacher and the motives or reasons why teacher applied those strategies in ELT interaction.

\section{LITERATURE REVIEW}

\section{Communication Accommodation Strategies}

Accommodation theory was firstly introduced by Giles in 1970s and known as speech accommodation theory (SAT) which concern on speech variability or verbal features (Dragojevic et al. 2015). Later, speech 
accommodation theory was developed and extended into nonverbal features and known as communication accommodation theory (CAT) in 1991. Communication accommodation theory deals with someone's ability to adjust and regulate behavior when interacting or responding to others (Gallois and Giles 2015). The substance of accommodation theory is actually the practice of adaptation when someone adjusts his or her communication. This theory rests on the premise if someone interacts in communication, they will adjust their speech, vocals, tone, accent, pace or body movement to accommodate others (Holmes and Wilson 2017). Moreover, in English language teaching context, teachers used communication accommodation strategies to adjust or bridge the gap of linguistic competence between teacher and students in classroom interaction. Womack (2017) mentioned that accommodate students' understanding becomes the basic act and art of teaching to maintain classroom interaction. Once again, it showed that teachers take an essential role to help students in delivering the materials through verbal or nonverbal language.

Moreover, there are two kinds of communication accommodation theory called as convergence and divergence strategies (Gallois and Giles 2015). Holmes \& Wilson (2017) explained that convergence is a part of accommodation strategies when someone involved in the interaction and tries to adapt the communicative behavior to be more similar to the interlocutor. The features of convergence strategies that cover verbal domain including the use of simpler vocabulary, repetition, same code, same pronunciation, code switching, translating and developing the topic (Dragojevic et al. 2015; Gallois and Giles 2015; Holmes and Wilson 2017). While the convergence strategies that cover nonverbal domain consist of extending the utterance length, pausing, smiling and gazing, expressive facial and head nodding, gesture and posture.

Furthermore, divergence is behavior when someone does not show any similarities between one another in interaction (Dragojevic, Gasiorek, and Giles 2016). However, divergence is not a condition to negate the response to the interlocutor but rather an attempt to show a difference to the interlocutor. In other word, convergence strategies are used to adjust the others in communication, while divergence to show the opposite direction or dissimilarities. In addition, some features of convergence strategies that cover the verbal and nonverbal domain include the way someone maintains the language uses, show the different code, change the topic, use different pronunciation and vocabularies, use nonexpressive posture and gesture, also shifting the speech rate (Dragojevic et al. 2015; Gallois and Giles 2015; Holmes and Wilson 2017). 


\section{The Motives in Communication Accommodation Strategies}

The communication accommodation strategies ware supported by the theory that explored the motives of someone in doing those strategies (Dragojevic et al. 2015). Someone's purpose in doing something whether it is conscious or unconscious is called as motives. The motives of accommodation related to the way someone explains or gives the reason for his behavior during the conversation. In short, someone's motive in doing convergence strategy is to show the closeness. Zhang \& Giles (2017) mentioned that convergence strategy is applied to get approval by adjusting the interlocutor's linguistic style for effective communication. Besides the motive of divergence strategy is used by speaker to emphasize the dissimilarity with interlocutor. Furthermore, the motives of speaker in applying the communication accommodation strategies in interaction were classified into affective and cognitive motives (Dragojevic et al. 2015).

First, affective motives take place in both convergence and divergence of accommodative strategies. According to Dragojevic et al., (2016), affective motives in convergence strategies is used to gain or give the approval in conversation to be more recognized in the circle or group. It can be said that affective motives are the intention to show the closeness and avoid the distance with interlocutor. In ELT context, teacher tries to adjust the speech style or linguistic variation to establish the closeness with students. If the relation between teacher and students run well, students will easily understand the message delivered. Moreover, affective motives of divergence strategy are used to emphasize the difference of identity or distance between speaker and interlocutor (Dragojevic et al. 2015).

Second, cognitive motives relate to someone's intention to reach an understandable conversation with others. The term cognitive is usually concern with someone's process in knowing and understanding certain circumstances. Dragojevic et al. (2016) explained that the speaker could facilitate the interlocutor's comprehensible input using accommodative strategies to reach the communicative interaction. It showed that cognitive motives underlie how the message could be easily understandable and predictable. Besides, teacher commonly uses the divergence strategies in order to facilitate students' linguistic resources in ELT class and it is classified as cognitive motives. Moreover, cognitive motives of divergence strategies are used to show the difference in perspective. It means that actually encourage someone's comprehension could be found by showing the distinctiveness to the interlocutor. For instance, slowing the speech rate rather than adjust the interlocutor fast pace is better to reach an understandable message. 


\section{RESEARCH METHOD}

This study employed the qualitative approach to describe the communication accommodation strategies performed by teacher in ELT class and the motives underlying its used. Creswell \& Poth (2016) explained that the explanation from someone's action and word could give a rich description in qualitative approach. The subject and setting of this study was one English teacher from $10^{\text {th }}$ grades of senior high school or secondary level. In the secondary level, students' communicative competence was highlighted as the learning objective. For that reason, teachers need to adjust their communicative style and students' competence using accommodative strategies to reach a comprehensive understanding.

As the data collection procedure, this study used classroom observation completed by a checklist to describe and specify the communication accommodation strategies performed by teacher in ELT interaction. The writer observed the interaction between teacher and students in ELT class for twice. Then, the writer conducted an unstructured interview to reveal and ask the reasons or motives behind the used of those features in accommodation strategies. In order to know the motives, the questions of interview were based on how teacher performed the accommodative strategies in ELT class. The writer recorded the interview process to avoid the miscommunication an in important part. In this study, the writer could gather the data by directly seeing the subject of the study behave, act or perform a certain thing, also talking face-to-face with the participant (Creswell and Creswell 2017).

Furthermore, this study analyzed the data based on Miles, Huberman, \& Saldana (2014) by summarize, display then make conclusion from the data. First, the data from checklist observation was categorized into the convergence or divergence features and the writer summarized the number of frequencies. Then, the writer showed the data in the table to clarify what kinds of accommodative strategies applied by teacher in ELT class. Second, the writer conducted an unstructured interview to see teacher's motives in applying CAT and transcribed the audio recording. Based on the transcription, the writer summarized or found the pattern whether the teachers' motives in applying CAT are categorized as affective or cognitive motives. Finally, this study displayed the data by giving the written description of each motive of accommodation.

\section{FINDINGS}

Based on the observation, the writer found some accommodative strategies used by the teacher in ELT class. The features of communication accommodation strategies performed by teacher in classroom interaction can be seen in the table below: 
Table 1. Communication Accommodation Strategies Used by Teacher

\begin{tabular}{|c|c|c|}
\hline \multicolumn{2}{|c|}{ Communication Accommodation Strategies } & \multirow{2}{*}{$\begin{array}{c}\begin{array}{c}\text { The number of } \\
\text { Frequencies }\end{array} \\
23 \\
\end{array}$} \\
\hline \multirow{12}{*}{$\begin{array}{l}\text { Convergence } \\
\text { Features }\end{array}$} & Using simpler vocabulary & \\
\hline & Using repetition & 14 \\
\hline & Using the same code & 7 \\
\hline & Using the same pronunciation & 0 \\
\hline & Code-switching & 35 \\
\hline & Translating the difficult word & 17 \\
\hline & Developing the topic & 4 \\
\hline & Extending the utterance length & 10 \\
\hline & Using pause & 10 \\
\hline & Smiling and gazing & 6 \\
\hline & Expressive facial and head nodding & 9 \\
\hline & Gesture and posture & 18 \\
\hline \multirow{7}{*}{$\begin{array}{c}\text { Divergence } \\
\text { Features }\end{array}$} & Maintaining the language uses & 20 \\
\hline & Showing the different code & 7 \\
\hline & Changing the topic & 0 \\
\hline & Using different pronunciation & 10 \\
\hline & Using different vocabularies & 0 \\
\hline & Using non expressive gesture and posture & 0 \\
\hline & Shifting the speech rate & 15 \\
\hline
\end{tabular}

Based on the observation, English teacher tended to be more convergence in ELT interaction rather than divergence. Teacher used 11 out of 12 features of convergent in communication accommodation strategies to adjust students during English learning process. The most common divergence strategies based on the number of frequencies in ELT interaction was code-switching, using simpler vocabulary, using gestures and posture. Besides, the convergence features of communication accommodation strategies combined both verbal and nonverbal domains. Teacher used nonverbal domain of accommodative strategies in giving the expressive facial to students, pausing, smiling and gazing. The other convergence features used by teacher to adjust students in ELT interaction was extending the utterance length, translating the difficult message, repeat the certain word, making the same code and developing the topic. Once again, it clearly described that teacher adjust their students in ELT interaction.

On the other hand, the divergence features in communication accommodation strategies rarely used by teacher. The data from classroom observation showed that teacher only used 5 out of 7 features in divergence with less frequency compared to the convergence features. The most dominant features of divergence performed by teacher were maintaining the language used and shifting the speech rate. Besides, teacher also used the different pronunciation, code and vocabulary to show the distinctiveness from students in ELT interaction. 
None of nonverbal domains performed by teacher in divergence features of communication accommodation strategies since teacher only emphasized the verbal domain in ELT interaction.

\section{Teacher's Motives in Applying Communication Accommodation Strategies}

Affective Motives

Teacher used some communication accommodation strategies both convergence and divergence in ELT interaction with students. There were affective motives underlie the use of communication accommodation strategies in secondary ELT class. First, teacher has affective motives in performing some convergence features in the verbal domains such as developing the topic and using the same code. Teacher tried to develop the topic in every interaction to adjust and build the closeness with students. For example, teacher introduced one material to students and later teacher develop it into short stories that relate to lesson material. Students become more interested in the material given by teacher. It built the closeness between teacher and students in ELT class since students would give a response or questions regarding the story. Teacher also used the same code with students to avoid the social distance in conversation. Sometimes students were afraid to respond their teacher because they have lack linguistic references in English. Teacher avoided the distance by using the same code as the students use. For example, teacher responded to students who used the Indonesian language in conversation with the same code, so students did not feel nervous in classroom interaction. Moreover, affective motives appeared in the use of nonverbal domain in convergence features such as smiling and gazing, also using the expressive facial. The reason why teacher performed nonverbal domain in the form of smiling and gazing in ELT class was to give the approval to students. Teacher presented the approval in the form of smiling if students spoke the right answer and gazed at them to emphasize the closeness during the conversation. It also happened when teacher put on the expressive facial to communicate the interest or agreement in ELT interaction with students.

Second, affective motives also underlie the use of divergence features such as shifting the speech rate. Shifting the speech rate in conversation was the second common feature in divergence. Teacher shifted her speech became slower or faster in order to decrease the distance between students in conversation. For instance, when students spoke with a faster speech rate, teacher did not adjust them by applying a faster speech too but rather slower her speech rate to maintain the closeness with students. 


\section{Cognitive Motives}

Based on the interview with teacher, there were cognitive motives underlying the use of communication accommodation strategies in convergence and divergence features. First, teacher has cognitive motives in performing some convergence features in the verbal domain such as code-switching, using simpler vocabulary, translating a difficult word, using repetition and pause the speech rate. Teacher adjusted her speech with students in ELT class using code switching in order to maintain students' understanding. Teacher used English language in delivering the material and then she can change their code easily into Indonesian language to respond her students in conversation. Other features used to enhance students' understanding in ELT class was using simpler vocabulary and translating the difficult word. Teacher avoided in using the complex words to adjust students' understanding in conversation, especially when teacher met with students that are not active in classroom interaction. Besides, translating the difficult message became one of the strategies to make sure that students understand the material delivered by teacher in ELT class. Teacher also extend her utterance length to adjust students' understanding by giving more explanation about the material and using the pause to build an effective communication. Moreover, teacher performed nonverbal domains in convergence features such as using gestures and posture. In fact, giving a response in the form of gesture or posture could support students' understanding of English material. For instance, rather than explaining if "surfing" was playing in the middle of the waves with a board, teacher would shake her hand up and down so students can guess the meaning through nonverbal gestures. It shows that adjustments through nonverbal could make students think more critically.

Second, cognitive motives also underlie the use of divergence features such as maintaining the language used, using different code and pronunciation. Maintaining the language became the most common divergence features used by teacher. In order to encourage students to use English language in conversation, teacher maintains the language on her own and prefers to use a different code from students. It means that teacher did not change her code or adjust students' in interaction. For example, when students spoke with Indonesian language, then teacher still maintain the used English as the different code from students. The result showed that students tried to use English to adjust the teacher's code as much as they could. Furthermore, during the interaction, teacher might perform a different pronunciation to give a sign that students pronounce a word incorrectly. According to teacher, it was the best way to tell them through the direct example to keep an effective communication in ELT class. 


\section{DISCUSSION}

Based on the finding, this study showed that teacher used more convergence rather than divergence in communication accommodation strategies. Teacher emphasized the adjustment to reach effective communication between teacher and students in ELT class. Maharsi (2010) also mentioned that the implementation of CAT could improve students' performance in English class. This study showed that teacher accommodates students to bridge the gap of linguistic competence between teacher and students, so students can actively participate in classroom interaction. Besides, divergence features in communication accommodation strategies also used by teacher in ELT class but not as much as convergence. During the teaching and learning process, teacher has to deal with students' fluency in speaking, so using convergence features in communication accommodation strategies is more suitable to adjust students' communicative competence. Matsuda (2017) supported that implementing the communication strategies in classroom interaction could motivate and expose students' communicative skills to negotiate their linguistic competence. Once again, enhancing students' communicative competence is important, as it becomes one of the objectives of English study in our curriculum. It was different from Rachmawaty \& Hermagustiana (2015) that tried to solve students' problems in speaking fluency in English class using retelling techniques.

The finding of this study also revealed that both verbal and nonverbal domains appeared in communication accommodation strategies in ELT class. It renewed the existing study from Jumiati et al., (2017) that concluded if nonverbal domain was limited to be described using communication strategies. Based on the finding, teacher applied 8 verbal domains and 3 nonverbal domains of convergence features and 4 verbal domains of divergence features in communication accommodation strategies. As Bambaeeroo \& Shokrpour (2017) mentioned in their study that nonverbal language is highly reliable to complement the classroom communication for teacher's successes in teaching.

Furthermore, teacher has both affective and cognitive motives in performing communication accommodation strategies in secondary ELT class. Besides, cognitive motives were more dominant in the use of CAT in ELT class. In affective motives, teacher emphasized the closeness and approval from students. The use of some convergence features such as developing the topic, using the same code, smiling, gazing, and expressive facial underlie the affective motives in teacher-student interaction. While shifting the speech rate became slower or faster also included in affective motives from divergence features to decrease the distance between students in conversation. In line with a study from Chen (2019) which teacher has affective motive in applying communication accommodation by avoiding the impolite language to adult students in order to 
build solidarity. In addition, teacher has cognitive motives in applying communication accommodation strategies to enhance students' understanding of material delivered by teacher in ELT class. The use of some convergence features such as code switching, translating a difficult message, using simpler vocabulary, posture and gesture underlie the cognitive motives as teacher want to fulfill students' communicative needs. Code switching became the dominant feature used by teacher in this study if it is compared to accommodation in classroom code-switching from Tien (2009). Besides, teacher built the effective communication and encourages students' critical thinking by performing some divergence features such as maintaining the language used, using different code and different pronunciation.

\section{CONCLUSION}

Finally, it can be concluded that communication accommodation strategies performed by teacher in secondary ELT class could help students to improve their communicative competence. This study showed that accommodative strategies applied by teacher was combined both verbal and nonverbal domain. The importance of communication accommodation strategies in ELT interaction was supported by teacher's affective motives to build the closeness with students and cognitive motives to enhance students' understanding in ELT class.

\section{REFERENCES}

Bambaeeroo, Fatemeh, \& Nasrin, S. (2017). The Impact of the Teachers' NonVerbal Communication on Success in Teaching. Journal of Advances in Medical Education \& Professionalism 5(2):51-60

Cahyono, B., Y, \& Utami, W. (2015). The Teaching of EFL Vocabulary in the Indonesian Context: The State of the Art. TEFLIN Journal 19(1):1-17.

Chen, C., H. (2019). Exploring Teacher-Student Communication in SeniorEducation Contexts in Taiwan: A Communication Accommodation Approach. International Journal of Ageing and Later Life, 13(1):63-109.

Creswell, J., W., \& J. David, Cl. (2017). Research Design: Qualitative, Quantitative, and Mixed Methods Approaches. Sage publications.

Creswell, J., W., \& Cheryl, N., P. (2016). Qualitative Inquiry and Research Design: Choosing among Five Approaches. Sage publications.

Dragojevic, M, Jessica, G, \& Howard, G. (2015). Communication Accommodation Theory. 1-21 in The International Encyclopedia of Interpersonal Communication, edited by C. R. Berger and M. E. Roloff. New York, USA: John Wiley \& Sons, Inc.

Dragojevic, Marko, Jessica, G, \& Howard, G. (2016). Accommodative Strategies as Core of the Theory. 36-59 in Communication accommodation theory: Negotiating personal relationships and social identities across contexts, edited by H. Giles. United Kingdom: Cambridge University Press. 
Gallois, Cindy, \& Howard, G. (2015). Communication Accommodation Theory. in The international encyclopedia of language and social interaction, edited by K. Tracy, C. Ilie, and T. Sandel. New York, US: John Wiley \& Sons, Inc.

Holmes, Janet, N., \& Wilson. (2017). An Introduction to Sociolinguistics. 5 Ed. Routledge, Taylor and Francis Group.

Jumiati, Sofyan, A. Gani, \& Diana, F., S. (2017). Communication Strategies Used by the English Teacher in Teaching Speaking Skill." Research in English and Education 2(4):53-62.

Kääntä, L. (2015). The Multimodal Organisation of Teacher-Led Classroom Interaction." in International perspectives on ELT classroom interaction, edited by C. J. Jenk and P. Seedhouse. London: Palgave Macmillan.

Maharsi, E. (2010). Converging and Diverging in EFL Speaking Class. Jurnal Humanitas 6(1):1-15.

Markee, N. (2015). The Handbook of Classroom Discourse and Interaction. United Kingdom: John Wiley \& Sons, Inc.

Matsuda, A. (2017). Preparing Teachers to Teach English as an International Language. Bristol, UK: Multilingual Matters Publiser.

Miles, M, A. M. Huberman, \& Johnny, S. (2014). Qualitative Data Analysis: A Methods Sourcebook. Thousand Oaks, California: Sage Publications, Inc.

Parcha, J., M. 2014. Accommodating Twitter: Communication Accommodation Theory and Classroom Interactions. Communication Teacher Journal 28(4):229-35.

Rachmawaty, Noor, \& Istanti, H. (2015). Des Retelling Technique Improve Speaking Fluency? TEFLIN Journal 21(1):1-8.

Rastegar, Mina, \& Samira S., M., G. (2016). Communication Strategies, Attitude, and Oral Output of EFL Learners: A Study of Relations. Open Journal of Modern Linguistics 6(5):401-19.

Sedova, Klara, Martin, S., \& Roman, S. (2016). Teacher Professional Development as a Means of Transforming Student Classroom Talk. Journal of Teaching and Teacher Education 57(1):14-25.

Tien, C. (2009). Conflict and Accommodation in Classroom Codeswitching in Taiwan. International Journal of Bilingual Education and Bilingualism 12(2):173-92.

Weizheng, Z. (2019). Teacher-Student Interaction in EFL Classroom in China: Communication Accommodation Theory Perspective. English Language Teaching Journal 12(12):99-111.

Womack, A. (2017). Teaching Is Accommodation: Universally Designing Composition Classrooms and Syllabi. College Composition and Communication Journal 68(3):494-525.

Zhang, Y., B, \& Howard, G. (2017). Communication Accommodation Theory. in The international encyclopedia of intercultural communication, edited by Y. Y. Kim and K. L. McKay-Semmler. New York, US: Wiley Online Library. 